\title{
Desempenho de concretos com agregados reciclados de cerâmica vermelha
}

\section{(Performance of red ceramic recycled aggregate concrete)}

\author{
A.E.B.Cabral ${ }^{1}$,V.Schalch ${ }^{2}$,D.C.C.Dal Molin ${ }^{3}$,J.L.D.Ribeiro ${ }^{4}$, Rasiah Sri Ravindrarajah ${ }^{5}$ \\ ${ }^{1}$ Departamento de Engenharia Estrutural e Construção Civil - DEECC, Universidade Federal do Ceará - UFC, \\ Campus Universitário do Pici, Bloco 710, Fortaleza, CE, Brasil 60455-760 \\ ${ }^{2}$ Escola de Engenharia de S. Carlos, Universidade de S. Paulo - EESC/USP, \\ Av. Trabalhador Sancarlense 400, Centro, S. Carlos, SP, Brasil 13560-000 \\ ${ }^{3}$ Núcleo Orientado para a Inovação da Edificação - NORIE, Universidade Federal do Rio Grande do Sul - UFRGS \\ Av. Oswaldo Aranha, 99, $3^{\circ}$, Porto Alegre, RS, Brasil 90035-190 \\ ${ }^{4}$ Laboratório de Otimização de Produtos e Processos - LOPP, Universidade Federal do Rio Grande do Sul - UFRGS \\ Praça Argentina 9, Centro, Porto Alegre, RS, Brasil 90040-020 \\ ${ }^{5}$ Faculty of Engineering, University of Technology, Sydney - UTS, PO Box 123, Broadway, NSW 2007, Australia \\ antedu@gmail.com,vschalch@sc.usp.br,dmolin@ufrgs.br,ribeiro@producao.ufrgs.br,ravir@eng.uts.edu.au
}

\section{Resumo}

Os resíduos de construção e demolição (RCD) constituem uma importante parcela dos resíduos sólidos produzidos nas cidades brasileiras, correspondendo em torno de $50 \%$ dos resíduos sólidos urbanos. Dentre os diversos constituintes do RCD, a cerâmica vermelha, proveniente de restos de tijolos e telhas cerâmicas utilizados nas construções, equivale a uma considerável parcela destes resíduos. A reciclagem do RCD para a produção de agregados reciclados tem se tornado uma prática cada vez mais comum, particularmente em cidades onde há uma inacessibilidade ou escassez de agregados naturais, proporcionando altos custos para adquiri-los. Com o intuito de se determinar o comportamento do agregado reciclado de cerâmica vermelha na produção de concretos, desenvolveu-se um programa experimental baseado em um projeto de experimentos onde se substituiu os agregados miúdos e graúdos naturais pelos seus respectivos reciclados, além de se variar a relação água/cimento. Os concretos produzidos foram analisados com relação a três propriedades: resistência à compressão, módulo de deformação e volume de poros permeáveis (VPP). Os resultados obtidos foram analisados utilizando-se ferramentas estatísticas, desenvolvendo-se modelos matemáticos que descrevem o comportamento das propriedades estudadas ao se substituir o agregado natural pelos reciclados de cerâmica vermelha. Todos os modelos obtiveram excelentes coeficientes de determinação, acima de $95 \%$. Simulações realizadas utilizando-se os modelos propostos apontam que a substituição do agregado miúdo natural pelo miúdo reciclado resulta em um acréscimo da resistência à compressão dos concretos produzidos e para a substituição do agregado graúdo natural pelo graúdo reciclado, um decréscimo. Para as demais propriedades do concreto estudadas, observou-se que a utilização dos agregados reciclados, tanto graúdo quanto miúdo, influi negativamente no comportamento do concreto, sendo que o agregado do tipo graúdo reciclado exerceu em todas as propriedades, uma maior influência.

Palavras-chave: cerâmica vermelha, reciclagem, agregado reciclado, concreto.

\begin{abstract}
Construction and Demolition (C\&D) waste is an important portion of solid waste produced in Brazilian cities, corresponding around $50 \%$ of urban solid wastes. Among several representatives of $C \& D$ waste, red ceramic, originated from bricks and tiles used in constructions, is a considerable portion. The recycling of $C \& D$ waste making recycled aggregates has been a common practice, particularly in cities where there is an inaccessibility or shortage of natural aggregates, that propitiate high costs to acquire them. Intending determine the behavior of red ceramic recycled aggregates in concrete's production, it was made an experimental program based on a project of experiments. In this program, the fine and the coarse natural aggregates were substituted by theirs respective recycled aggregates. The water/cement ratio was also varied. The produced concretes were analyzed regarding three properties: axial strength, modulus of deformation and volume of permeable voids (VPP). All the proposed models had excellent determination coefficient, higher than 95\%. Simulations were made using the proposed models. The results indicate the natural fine aggregate substitution by the recycled red ceramic fine aggregate results in an axial strength increment and for a natural coarse aggregate substitution by the recycled red ceramic coarse aggregate, a decrease. For the other concrete properties, it was observed that the recycled aggregate use, as for coarse as for fine aggregate, had a negative effect and the recycled coarse aggregate exercised a larger influence than the fine aggregate.
\end{abstract}

Keywords: red ceramic, recycling, recycled aggregate, concrete.

\section{INTRODUÇÃO}

A indústria da construção civil é um setor produtivo que possui considerável papel na economia do Brasil. Entre 1980 e 1996 o setor foi responsável por 65\% da formação do investimento bruto nacional. Em 1999 o setor já alcançava 
$70 \%$ do investimento da economia brasileira. No ano de 2001 o setor foi responsável por 15,6\% do PIB, sendo que as edificações residenciais representaram um montante entre $6 \%$ e $9 \%$ do PIB nacional [1]. Para alavancar tamanha grandiosidade, a indústria da construção civil é atualmente a maior consumidora de recursos naturais da sociedade, absorvendo de 20 a $50 \%$ desses recursos explorados no mundo [2]. No caso da madeira, a Indústria da Construção Civil consome aproximadamente dois terços de toda a madeira natural extraída da natureza [3]. As atividades de construção demandam uma notável quantidade de materiais inertes, tais como areia e cascalho, que usualmente são fornecidos por meio da extração de sedimentos aluviais. A extração desses sedimentos modifica o perfil dos rios e o seu equilíbrio, além de introduzir problemas ambientais, tais como modificações em sua estrutura hidrológica e hidrogeológica. A extração de material inerte de formações rochosas em áreas acidentadas e montanhosas também é uma danosa atividade ao meio ambiente, uma vez que altera a paisagem e provoca problemas de estabilidade [4]. Se nada for feito, a indústria do concreto irá consumir anualmente de 8 a 12 bilhões de toneladas de agregados naturais até o ano 2010 [5].

Como em todo processo industrial, o uso dos insumos da indústria da construção civil gera resíduos em grande escala, que necessitam ser gerenciados. O macrocomplexo da indústria da construção civil é responsável por $40 \%$ dos resíduos gerados na economia [2]. Em 1992 era estimada a produção de aproximadamente 50 milhões de toneladas de resíduos das atividades da construção civil na comunidade européia, 60 milhões nos Estados Unidos e 12 milhões somente no Japão [6]. Estima-se que a maioria dos resíduos da construção civil seja proveniente de serviços de demolição e dos canteiros de obra, ou seja, dos serviços de construção. Devido a isto, os resíduos da construção civil também são chamados de resíduos de construção e demolição (RCD). Um ponto que demonstra a relevância dos RCD é a sua crescente participação no total dos resíduos sólidos urbanos (RSU). Exemplificando, dados da cidade de Salvador apontam que no período de 1990 a 2000, o RCD aumentou a sua participação na composição dos RSU de 4,4\% para $49,8 \%$ [7]. A composição dos RCD é variável, em função da região geográfica, da época do ano, do tipo de obra, dentre outros fatores. Quando oriundos de obras de construção, a composição é dependente do estágio da obra, uma vez que no estágio de concretagem da estrutura há uma maior incidência de fragmentos de concreto, aço, formas de madeira, entre outros materiais, enquanto que no estágio de acabamento, há predominância de restos de argamassa, tijolos, telhas e placas cerâmicas. Caso a obra seja uma reforma, haverá uma incidência maior de materiais cerâmicos, madeira, rochas naturais, vidro, metais e plásticos [8,9].

No Brasil, estima-se que em média $65 \%$ do material descartado é de origem mineral, $13 \%$ madeira, $8 \%$ plásticos e $14 \%$ outros materiais [10]. Estima-se também que argamassa, concreto e cerâmica vermelha correspondem, juntos, a mais de $60 \%$ do total do RCD gerado [11], enquanto que na
Europa, esses materiais correspondem a algo em torno de $50 \%$ do total do RCD [12]. Especificamente sobre os resíduos de cerâmica vermelha, estima-se que estes correspondam, em média, a 30\% do total dos RCD produzidos nas cidades brasileiras [11]. Essa elevada geração de resíduos de cerâmica vermelha parece ocorrer também em outros países, uma vez que estima-se que $30 \%$ da produção diária da indústria cerâmica da Índia torna-se resíduo [14] e que no Irã, em 1994, eram produzidos cerca de 350 mil toneladas de resíduos de cerâmica vermelha, como restos de tijolos e telhas [13]. Embora estes resíduos possam ser reaproveitados no próprio processo de produção dos artefatos cerâmicos da indústria cerâmica [15], a reciclagem destes, na produção de agregados reciclados para uso na própria construção civil, pode ser uma solução adotada no seu gerenciamento, em função do grande volume de agregados que são usados pela indústria da construção civil.

Com o intuito de contribuir nesta área de conhecimento, por meio dos resultados obtidos em um programa experimental baseado em um projeto fatorial fracionado composto de segunda ordem, que contempla a produção de concretos com os três principais componentes do RCD (concreto, argamassa e cerâmica vermelha), modelou-se o comportamento da resistência à compressão $(f)$, do módulo de deformação $\left(E_{c}\right)$ e do volume de poros permeáveis $(V P P)$ dos concretos produzidos, ao se variar o teor de substituição dos agregados naturais pelos reciclados e a relação água/ cimento. Entretanto, neste trabalho, será apresentado somente o comportamento do concreto ao se utilizar os agregados reciclados de cerâmica vermelha.

\section{MATERIAIS E MÉTODOS}

\section{Projeto experimental}

Para a elaboração do projeto experimental foram identificadas sete variáveis independentes (fatores): os agregados miúdo e graúdo reciclados de cerâmica vermelha, os agregados miúdo e graúdo reciclados de argamassa, os agregados miúdo e graúdo reciclados de concreto e a relação água/cimento. Identificaram-se também três variáveis dependentes: a resistência à compressão, o módulo de deformação e o volume de poros permeáveis. Por meio do projeto de experimentos fatoriais $2^{k}$ pode-se avaliar, com propriedade, o efeito conjunto de todos esses 7 fatores sobre as variáveis de resposta [16], sendo que a execução deste projeto de experimentos consiste em realizar $2^{7}$ traços de concreto, ou seja, 128 traços, o que demandaria elevados custos e grande demanda de tempo. A solução encontrada para viabilizar a execução da parte experimental, com elevado grau de confiabilidade dos resultados, foi o uso do projeto composto de segunda ordem. O projeto composto de segunda ordem tem como base um projeto fatorial $2^{\mathrm{k}}$, fracionado, onde soma-se a este último, todos os $2 . \mathrm{k}$ vértices de uma estrela e os pontos centrais da estrela e do projeto fatorial [16]. Os experimentos fatoriais fracionados são muito úteis quando há um grande número de fatores a serem 
Tabela I - Traços de concreto definidos pelo fracionamento do experimento.

[Table I - Concrete mixtures defined by factorial experiment.]

\begin{tabular}{|c|c|c|c|c|c|c|c|c|c|}
\hline \multirow[b]{2}{*}{ Traço $\mathrm{n}^{\mathrm{o}}$} & \multirow[b]{2}{*}{$\mathrm{a} / \mathrm{c}$} & \multicolumn{4}{|c|}{ Porcentagem de agregado graúdo no traço de concreto } & \multicolumn{4}{|c|}{ Porcentagem de agregado miúdo no traço de concreto } \\
\hline & & $\begin{array}{l}\text { Agregado } \\
\text { natural }\end{array}$ & $\begin{array}{l}\text { Agregado } \\
\text { reciclado de } \\
\text { concreto }\end{array}$ & $\begin{array}{c}\text { Agregado } \\
\text { reciclado } \\
\text { de cerâmica } \\
\text { vermelha }\end{array}$ & $\begin{array}{l}\text { Agregado } \\
\text { reciclado de } \\
\text { argamassa }\end{array}$ & $\begin{array}{c}\text { Agregado } \\
\text { natural }\end{array}$ & $\begin{array}{l}\text { Agregado } \\
\text { reciclado de } \\
\text { concreto }\end{array}$ & $\begin{array}{l}\text { Agregado } \\
\text { reciclado } \\
\text { de cerâmica } \\
\text { vermelha }\end{array}$ & $\begin{array}{l}\text { Agregado } \\
\text { reciclado de } \\
\text { argamassa }\end{array}$ \\
\hline 01 & 0,46 & $100 \%$ & $0 \%$ & $0 \%$ & $0 \%$ & $100 \%$ & $0 \%$ & $0 \%$ & $0 \%$ \\
\hline 02 & 0,74 & $100 \%$ & $0 \%$ & $0 \%$ & $0 \%$ & $0 \%$ & $0 \%$ & $100 \%$ & $0 \%$ \\
\hline 03 & 0,74 & $100 \%$ & $0 \%$ & $0 \%$ & $0 \%$ & $0 \%$ & $100 \%$ & $0 \%$ & $0 \%$ \\
\hline 04 & 0,46 & $100 \%$ & $0 \%$ & $0 \%$ & $0 \%$ & $0 \%$ & $50 \%$ & $50 \%$ & $0 \%$ \\
\hline 05 & 0,74 & $0 \%$ & $0 \%$ & $0 \%$ & $100 \%$ & $0 \%$ & $0 \%$ & $0 \%$ & $100 \%$ \\
\hline 06 & 0,46 & $0 \%$ & $0 \%$ & $0 \%$ & $100 \%$ & $0 \%$ & $0 \%$ & $50 \%$ & $50 \%$ \\
\hline 07 & 0,46 & $0 \%$ & $0 \%$ & $0 \%$ & $100 \%$ & $0 \%$ & $50 \%$ & $0 \%$ & $50 \%$ \\
\hline 08 & 0,74 & $0 \%$ & $0 \%$ & $0 \%$ & $100 \%$ & $0 \%$ & $33 \%$ & $33 \%$ & $33 \%$ \\
\hline 09 & 0,46 & $0 \%$ & $0 \%$ & $100 \%$ & $0 \%$ & $0 \%$ & $0 \%$ & $0 \%$ & $100 \%$ \\
\hline 10 & 0,74 & $0 \%$ & $0 \%$ & $100 \%$ & $0 \%$ & $0 \%$ & $0 \%$ & $50 \%$ & $50 \%$ \\
\hline 11 & 0,74 & $0 \%$ & $0 \%$ & $100 \%$ & $0 \%$ & $0 \%$ & $50 \%$ & $0 \%$ & $50 \%$ \\
\hline 12 & 0,46 & $0 \%$ & $0 \%$ & $100 \%$ & $0 \%$ & $0 \%$ & $33 \%$ & $33 \%$ & $33 \%$ \\
\hline 13 & 0,74 & $0 \%$ & $0 \%$ & $50 \%$ & $50 \%$ & $100 \%$ & $0 \%$ & $0 \%$ & $0 \%$ \\
\hline 14 & 0,46 & $0 \%$ & $0 \%$ & $50 \%$ & $50 \%$ & $0 \%$ & $0 \%$ & $100 \%$ & $0 \%$ \\
\hline 15 & 0,46 & $0 \%$ & $0 \%$ & $50 \%$ & $50 \%$ & $0 \%$ & $100 \%$ & $0 \%$ & $0 \%$ \\
\hline 16 & 0,74 & $0 \%$ & $0 \%$ & $50 \%$ & $50 \%$ & $0 \%$ & $50 \%$ & $50 \%$ & $0 \%$ \\
\hline 17 & 0,46 & $0 \%$ & $100 \%$ & $0 \%$ & $0 \%$ & $0 \%$ & $0 \%$ & $0 \%$ & $100 \%$ \\
\hline 18 & 0,74 & $0 \%$ & $100 \%$ & $0 \%$ & $0 \%$ & $0 \%$ & $0 \%$ & $50 \%$ & $50 \%$ \\
\hline 19 & 0,74 & $0 \%$ & $100 \%$ & $0 \%$ & $0 \%$ & $0 \%$ & $50 \%$ & $0 \%$ & $50 \%$ \\
\hline 20 & 0,46 & $0 \%$ & $100 \%$ & $0 \%$ & $0 \%$ & $0 \%$ & $33 \%$ & $33 \%$ & $33 \%$ \\
\hline 21 & 0,74 & $0 \%$ & $50 \%$ & $0 \%$ & $50 \%$ & $100 \%$ & $0 \%$ & $0 \%$ & $0 \%$ \\
\hline 22 & 0,46 & $0 \%$ & $50 \%$ & $0 \%$ & $50 \%$ & $0 \%$ & $0 \%$ & $100 \%$ & $0 \%$ \\
\hline 23 & 0,46 & $0 \%$ & $50 \%$ & $0 \%$ & $50 \%$ & $0 \%$ & $100 \%$ & $0 \%$ & $0 \%$ \\
\hline 24 & 0,74 & $0 \%$ & $50 \%$ & $0 \%$ & $50 \%$ & $0 \%$ & $50 \%$ & $50 \%$ & $0 \%$ \\
\hline 25 & 0,46 & $0 \%$ & $50 \%$ & $50 \%$ & $0 \%$ & $100 \%$ & $0 \%$ & $0 \%$ & $0 \%$ \\
\hline 26 & 0,74 & $0 \%$ & $50 \%$ & $50 \%$ & $0 \%$ & $0 \%$ & $0 \%$ & $100 \%$ & $0 \%$ \\
\hline 27 & 0,74 & $0 \%$ & $50 \%$ & $50 \%$ & $0 \%$ & $0 \%$ & $100 \%$ & $0 \%$ & $0 \%$ \\
\hline 28 & 0,46 & $0 \%$ & $50 \%$ & $50 \%$ & $0 \%$ & $0 \%$ & $50 \%$ & $50 \%$ & $0 \%$ \\
\hline 29 & 0,74 & $0 \%$ & $33 \%$ & $33 \%$ & $33 \%$ & $0 \%$ & $0 \%$ & $0 \%$ & $100 \%$ \\
\hline 30 & 0,46 & $0 \%$ & $33 \%$ & $33 \%$ & $33 \%$ & $0 \%$ & $0 \%$ & $50 \%$ & $50 \%$ \\
\hline 31 & 0,46 & $0 \%$ & $33 \%$ & $33 \%$ & $33 \%$ & $0 \%$ & $50 \%$ & $0 \%$ & $50 \%$ \\
\hline 32 & 0,74 & $0 \%$ & $33 \%$ & $33 \%$ & $33 \%$ & $0 \%$ & $33 \%$ & $33 \%$ & $33 \%$ \\
\hline 33 & 0,60 & $0 \%$ & $50 \%$ & $25 \%$ & $25 \%$ & $0 \%$ & $33 \%$ & $33 \%$ & $33 \%$ \\
\hline 34 & 0,60 & $0 \%$ & $0 \%$ & $50 \%$ & $50 \%$ & $0 \%$ & $33 \%$ & $33 \%$ & $33 \%$ \\
\hline 35 & 0,60 & $0 \%$ & $25 \%$ & $50 \%$ & $25 \%$ & $0 \%$ & $33 \%$ & $33 \%$ & $33 \%$ \\
\hline 36 & 0,60 & $0 \%$ & $50 \%$ & $0 \%$ & $50 \%$ & $0 \%$ & $33 \%$ & $33 \%$ & $33 \%$ \\
\hline 37 & 0,60 & $0 \%$ & $25 \%$ & $25 \%$ & $50 \%$ & $0 \%$ & $33 \%$ & $33 \%$ & $33 \%$ \\
\hline 38 & 0,60 & $0 \%$ & $50 \%$ & $50 \%$ & $0 \%$ & $0 \%$ & $33 \%$ & $33 \%$ & $33 \%$ \\
\hline 39 & 0,60 & $0 \%$ & $33 \%$ & $33 \%$ & $33 \%$ & $0 \%$ & $50 \%$ & $25 \%$ & $25 \%$ \\
\hline 40 & 0,60 & $0 \%$ & $33 \%$ & $33 \%$ & $33 \%$ & $0 \%$ & $0 \%$ & $50 \%$ & $50 \%$ \\
\hline 41 & 0,60 & $0 \%$ & $33 \%$ & $33 \%$ & $33 \%$ & $0 \%$ & $25 \%$ & $50 \%$ & $25 \%$ \\
\hline 42 & 0,60 & $0 \%$ & $33 \%$ & $33 \%$ & $33 \%$ & $0 \%$ & $50 \%$ & $0 \%$ & $50 \%$ \\
\hline 43 & 0,60 & $0 \%$ & $33 \%$ & $33 \%$ & $33 \%$ & $0 \%$ & $25 \%$ & $25 \%$ & $50 \%$ \\
\hline 44 & 0,60 & $0 \%$ & $33 \%$ & $33 \%$ & $33 \%$ & $0 \%$ & $50 \%$ & $50 \%$ & $0 \%$ \\
\hline 45 & 0,80 & $0 \%$ & $33 \%$ & $33 \%$ & $33 \%$ & $0 \%$ & $33 \%$ & $33 \%$ & $33 \%$ \\
\hline 46 & 0,40 & $0 \%$ & $33 \%$ & $33 \%$ & $33 \%$ & $0 \%$ & $33 \%$ & $33 \%$ & $33 \%$ \\
\hline 47 & 0,60 & $0 \%$ & $33 \%$ & $33 \%$ & $33 \%$ & $0 \%$ & $33 \%$ & $33 \%$ & $33 \%$ \\
\hline 48 & 0,60 & $0 \%$ & $33 \%$ & $33 \%$ & $33 \%$ & $0 \%$ & $33 \%$ & $33 \%$ & $33 \%$ \\
\hline 49 & 0,46 & $25 \%$ & $25 \%$ & $25 \%$ & $25 \%$ & $25 \%$ & $25 \%$ & $25 \%$ & $25 \%$ \\
\hline 50 & 0,74 & $25 \%$ & $25 \%$ & $25 \%$ & $25 \%$ & $25 \%$ & $25 \%$ & $25 \%$ & $25 \%$ \\
\hline
\end{tabular}


investigados sobre uma ou mais variáveis de resposta e se deseja uma otimização de tempo e custos para a obtenção dos resultados, pois o fracionamento consiste em dividir o projeto completo em dois ou mais blocos e ensaiar somente um desses blocos, escolhido aleatoriamente [17]. Este tipo de estudo utilizando ferramentas estatísticas já foi previamente executado por outras pesquisas nacionais e internacionais [18-20]. Para a parte experimental em questão, o projeto completo foi dividido em 4 blocos, tendo sido ensaiado somente um bloco, ou seja, 32 traços, que consistem exatamente aos traços de número 1 ao 32 da Tabela I. Como o experimento em questão possui 7 fatores, a estrela do projeto fatorial possui 14 vértices, que correspondem exatamente aos traços 33 ao 46 da Tabela I. Os traços 47 e 48 correspondem aos pontos centrais do projeto fatorial fracionado e da estrela de sete pontas, os quais são iguais. Os traços 49 e 50 foram inseridos no projeto experimental, uma vez que representam os momentos onde todos os agregados (reciclados e naturais) estão presentes no concreto, atribuindo como valores para a relação água/cimento, os terços inferior e superior, ou seja, 0,46 e 0,74 . A Tabela I concatena todos os traços de concreto definidos no planejamento de experimentos.

Comovariáveis de resposta, ou seja, variáveis dependentes têm-se a resistência à compressão axial dos concretos produzidos, medida de acordo com os procedimentos descritos em [21], o módulo de deformação dos concretos, determinados de acordo com [22] e o volume de poros permeáveis (VPP) dos concretos, segundo [23]. Convém ressaltar que embora o projeto experimental envolva outros tipos de agregados reciclados que não somente os agregados reciclados de cerâmica vermelha, ao se fazer a análise dos resultados considerou-se apenas a influência dos agregados reciclados de cerâmica vermelha sobre as variáveis de resposta. O comportamento dos concretos com os outros tipos de agregados foi objeto de outras publicações [24, 25]. Outras variáveis foram fixadas, tais como a idade de execução dos ensaios (28 dias para a resistência à compressão e para o módulo de deformação e 224 dias para o VPP) e a préumidificação dos agregados reciclados, para que estes não absorvessem a água de amassamento e não modificassem assim a relação água/cimento $(\mathrm{a} / \mathrm{c})$.

\section{Caracterização dos materiais}

Para a execução dos traços de concreto utilizou-se cimento Portland de Alta Resistência Inicial (CP V), obtido de depósitos de material de construção, cujas características químicas, físicas e mecânicas foram fornecidas pelos fabricantes. Os agregados graúdos e miúdos naturais também foram obtidos em depósitos de material de construção, sendo a areia proveniente da dragagem de leito de rio e a brita proveniente da britagem de rochas ígneas (basalto), enquanto que os agregados reciclados de cerâmica vermelha foram provenientes do processamento da fração de cerâmica de resíduos de construção e demolição (RCD) e de resíduos de olarias em britadores de mandíbulas e em moinhos de rolo, sendo o material resultante peneirado na peneira de malha
$19 \mathrm{~mm}$, em que a fração retida foi descartada e a passante foi re-peneirada na peneira de malha $4,8 \mathrm{~mm}$, separando-se assim os agregados miúdos dos graúdos. Para os agregados utilizados, determinaram-se a absorção de água, a massa específica e a massa unitária destes, de acordo com as respectivas normas de ensaio. Por fim, utilizou-se também aditivo super-plastificante isento de cloretos, desenvolvido para uso em concretos em geral, com base em uma cadeia de polímeros de éter carboxílico modificado e água proveniente da rede pública de distribuição.

\section{Produção dos concretos}

Após a realização dos ensaios de caracterização dos agregados, iniciou-se a produção dos concretos definidos no projeto experimental com a moldagem dos corpos-deprova para execução dos ensaios. Como primeiro passo desta etapa, fez-se uma dosagem experimental com os agregados naturais [26] fixando-se o abatimento medido pelo método do tronco de cone (slump test) em $12 \pm 2 \mathrm{~cm}$. Para a produção dos traços de concreto da Tabela I, que possuem substituição dos agregados naturais pelos reciclados, alguns ajustes foram necessários serem feitos. Primeiramente, foi realizado uma compensação do volume dos agregados reciclados a serem utilizados nos traços pré-determinados, pois a simples substituição da massa do agregado natural pela massa do agregado reciclado iria resultar em traços com volumes maiores de agregados reciclados, uma vez que a massa específica dos agregados reciclados é menor que a massa específica dos agregados naturais, demandando assim mais água e cimento para produzir traços equivalentes ao traço de referência, ou seja, àquele com agregados naturais. A compensação do volume dos agregados reciclados nos traços do projeto experimental foi feita segundo a Equação A.

$$
\mathrm{M}_{\mathrm{AR}}=\mathrm{M}_{\mathrm{AN}} \cdot \frac{\gamma_{\mathrm{AR}}}{\gamma_{\mathrm{AN}}}
$$

em que $\mathrm{M}_{\mathrm{AR}}=$ massa do agregado reciclado $(\mathrm{kg}), \mathrm{M}_{\mathrm{AN}}=$ massa do agregado natural $(\mathrm{kg}), \gamma_{\mathrm{AR}}=$ massa específica do agregado reciclado $\left(\mathrm{kg} / \mathrm{dm}^{3}\right), \gamma_{\mathrm{AN}}=$ massa específica do agregado natural $\left(\mathrm{kg} / \mathrm{dm}^{3}\right)$

Posteriormente, determinou-se qual seria a massa de água que teria de ser adicionada antes das concretagens aos agregados reciclados, para que estes a absorvessem, sendo então colocados na betoneira já pré-umedecidos, evitando assim que parte da água de amassamento fosse absorvida pelos agregados, o que perturbaria o processo de hidratação do cimento. Para essa pesquisa, seguiram-se as recomendações da NBR 15116/04 [27], que estabelece requisitos para o emprego de agregados reciclados de resíduos de construção civil e sugere que seja feita uma prémolhagem nos agregados reciclados com um teor de água de $80 \%$ da absorção deste agregado. Então, umedeceram-se os agregados reciclados, $10 \mathrm{~min}$ antes da mistura na betoneira, com $80 \%$ da água que seria absorvida em $24 \mathrm{~h}$ pela massa do agregado reciclado correspondente ao traço a ser executado. 
Após esse procedimento de pré-umidificação, produziuse os 49 traços de concreto restantes, conforme o projeto experimental, moldando-se 4 corpos-de-prova cilíndricos de $10 \mathrm{~cm}$ de diâmetro por $20 \mathrm{~cm}$ altura [28], para se realizar os ensaios de módulo de deformação e resistência à compressão. Moldaram-se ainda 2 corpos-de-prova prismáticos de 7,5 cm $\mathrm{x} 7,5 \mathrm{~cm}$ de seção transversal por $32,5 \mathrm{~cm}$ de comprimento [29], para o ensaio de determinação do volume de poros permeáveis (VPP). Todos os corpos-de-prova foram curados em câmara úmida até os 28 dias de idade, idade que os corpos-de-prova de resistência à compressão e de módulo de deformação foram ensaiados. Os demais corpos-de-prova foram retirados da câmara úmida nesta idade e colocados em uma câmara climatizada (temperatura igual a $23 \pm 1,7{ }^{\circ} \mathrm{C}$ e umidade igual a $50 \pm 4 \%$ ) até a data dos ensaios.

\section{RESULTADOS E DISCUSSÃO}

\section{Resultados dos ensaios de caracterização dos materiais}

O cimento utilizado foi o CP V (ARI, alta resistência inicial), cujas propriedades químicas, físicas e mecânicas foram fornecidas pelos fabricantes, conforme dados das Tabelas II e III, respectivamente.

Os agregados naturais utilizados foram adquiridos em depósitos de materiais de construção, sendo que a areia apresentou um módulo de finura (MF) 2,50 e a brita 6,59. Já os agregados reciclados de cerâmica vermelha apresentaram um MF 2,80 e 6,62 para as suas frações miúda e graúda, respectivamente. Foram determinadas também algumas características do agregado natural e do agregado reciclado de cerâmica vermelha, tais como a absorção de água, a massa específica e a massa unitária, de acordo com as respectivas normas de ensaio, estando os resultados dispostos nas Tabelas IV e V, para os agregados miúdos e graúdos, respectivamente. Foi feita análise de difração de raios X (DRX) dos agregados

Tabela II - Características químicas do cimento (fornecido pelo fabricante).

[Table II - Cement chemical characteristics (supplied by manufacturer).]

\begin{tabular}{cc}
\hline Composição química do clínquer & Teores (\%) \\
\hline Óxido de magnésio $(\mathrm{MgO})$ & 4,85 \\
Trióxido de enxofre $\left(\mathrm{SO}_{3}\right)$ & 3,10 \\
Óxido de cálcio livre $(\mathrm{CaO}$ livre $)$ & 1,31 \\
Óxido de alumínio $\left(\mathrm{Al}_{2} \mathrm{O}_{3}\right)$ & 4,40 \\
Óxido de silício $\left(\mathrm{SiO}_{2}\right)$ & 18,55 \\
Óxido de ferro $\left(\mathrm{Fe}_{2} \mathrm{O}_{3}\right)$ & 2,66 \\
Óxido de cálcio $(\mathrm{CaO})$ & 60,11 \\
Equivalente alcalino & 0,59 \\
Resíduo insolúvel & 0,76 \\
Perda ao fogo & 3,46 \\
\hline
\end{tabular}

Tabela III - Características físicas e mecânicas do cimento (fornecido pelo fabricante).

[Table III - Cement physics and mechanical characteristics (supplied by manufacturer).]

\begin{tabular}{lll}
\hline \multicolumn{1}{c}{ Ensaio } & & Resultado \\
\hline Área específica (Blaine) & & $4916 \mathrm{~cm}^{2} / \mathrm{g}$ \\
Tempo de pega & Início & $185 \mathrm{~min}$ \\
& Fim & $245 \mathrm{~min}$ \\
Resistència & 1 dia & $30,8 \mathrm{MPa}$ \\
à & 3 dias & $39,5 \mathrm{MPa}$ \\
compressão & 7 dias & $44,9 \mathrm{MPa}$ \\
& 28 dias & $51,5 \mathrm{MPa}$ \\
\hline
\end{tabular}

Tabela IV - Características dos agregados miúdos. [Table IV - Fine aggregate characteristics.]

\begin{tabular}{cccc}
\hline & \multicolumn{3}{c}{ Método de ensaio } \\
& NM 30/00 & $\begin{array}{c}\text { NBR } \\
9776 / 87\end{array}$ & NM 45/02 \\
\hline Agregado & $\begin{array}{c}\text { Absorção } \\
(\%)\end{array}$ & $\begin{array}{c}\text { Massa } \\
\text { específica } \\
\left(\mathrm{g} / \mathrm{cm}^{3}\right)\end{array}$ & $\begin{array}{c}\text { Massa } \\
\text { unitária } \\
\left(\mathrm{g} / \mathrm{cm}^{3}\right)\end{array}$ \\
$\begin{array}{c}\text { Miúdo natural } \\
\text { Miúdo reciclado } \\
\text { de cerâmica } \\
\text { vermelha }\end{array}$ & 0,42 & 2,64 & 1,44 \\
\hline
\end{tabular}

Tabela V - Características dos agregados graúdos. [Table V-Coarse aggregate characteristics.]

\begin{tabular}{|c|c|c|c|}
\hline & \multicolumn{3}{|c|}{ Método de ensaio } \\
\hline & $\begin{array}{c}\mathrm{NM} \\
53 / 02\end{array}$ & NM 53/02 & NM 45/02 \\
\hline Agregado & $\begin{array}{c}\text { Absorção } \\
(\%)\end{array}$ & $\begin{array}{l}\text { Massa } \\
\text { específica } \\
\left(\mathrm{g} / \mathrm{cm}^{3}\right)\end{array}$ & $\begin{array}{l}\text { Massa } \\
\text { unitária } \\
\left(\mathrm{g} / \mathrm{cm}^{3}\right)\end{array}$ \\
\hline Graúdo natural & 1,22 & 2,87 & 1,56 \\
\hline $\begin{array}{l}\text { Graúdo reciclado } \\
\text { de cerâmica } \\
\text { vermelha }\end{array}$ & 15,62 & 1,86 & 1,26 \\
\hline \multicolumn{4}{|c|}{$\begin{array}{l}\text { reciclados de cerâmica vermelha, sendo que para se realizar } \\
\text { esse ensaio, depois de triturados, moeu-se manualmente } \\
\text { uma amostra de cada tipo de agregado reciclado até que a } \\
\text { grande maioria de suas partículas fosse passante na peneira } \\
\text { de } \mathrm{n}^{\circ} 200(0,075 \mathrm{~mm}) \text {. Após peneirado foi feita a análise por } \\
\text { difração de raios X, Fig. } 1 \text {. } \\
\text { Conforme os resultados apresentados nas Tabelas IV e V, } \\
\text { os agregados reciclados de cerâmica vermelha apresentaram }\end{array}$} \\
\hline
\end{tabular}




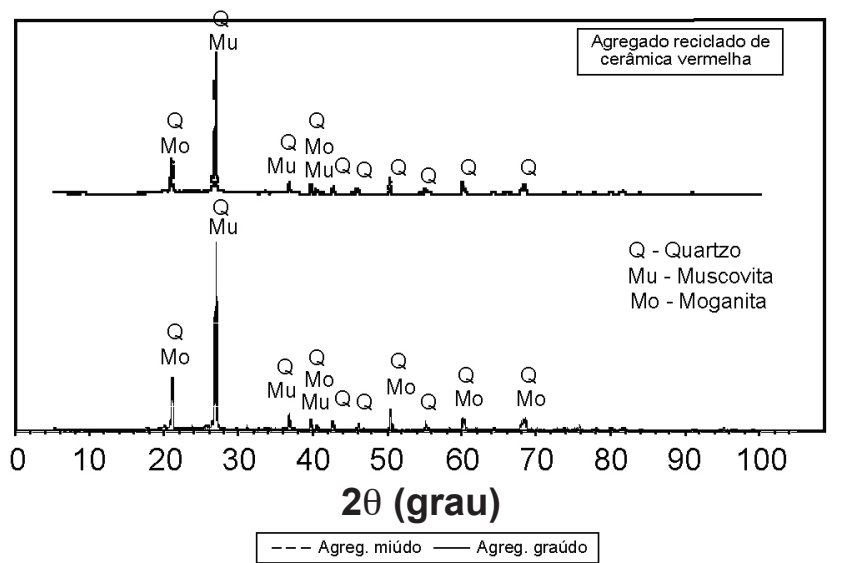

Figura 1: Difratogramas de raios $\mathrm{X}$ dos agregados miúdos e graúdos reciclados de cerâmica vermelha.

[Figure 1: X-ray diffraction patterns of fine and coarse red ceramic recycled aggregates.]

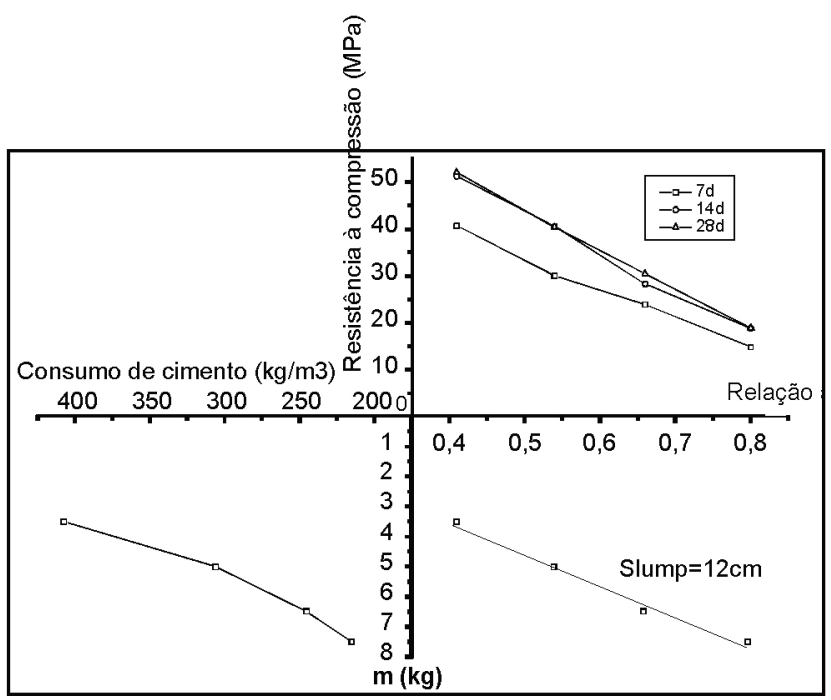

Figura 2: Diagrama de dosagem dos concretos.

[Figure 2: Concrete dosage diagram.]

Tabela VI - Composição do concreto de relação a/c igual a 0,46 , feito com agregados naturais.

[Table VI - Concrete's composition with w/c equal to 0,46 made with natural aggregates.]

\begin{tabular}{cccc}
\hline $\begin{array}{c}\text { Cimento } \\
(\mathrm{kg})\end{array}$ & $\begin{array}{c}\text { Agregado } \\
\text { miúdo } \\
(\mathrm{kg})\end{array}$ & $\begin{array}{c}\text { Agregado } \\
\text { graúdo } \\
(\mathrm{kg})\end{array}$ & $\begin{array}{c}\text { Água } \\
(\mathrm{kg})\end{array}$ \\
\hline 5,952 & 9,642 & 15 & 2,738 \\
\hline
\end{tabular}

uma maior absorção de água e menores massa específica e massa unitária que as dos agregados naturais. Com isso, pode-se inferir que os agregados reciclados de cerâmica vermelha são mais porosos que os agregados naturais.

Na Fig. 1 os agregados reciclados de cerâmica vermelha são compostos basicamente por quartzo (sendo este proveniente, em sua maior fração, da argila magra), muscovita (argilomineral do grupo das micas) e moganita, estando este resultado de acordo com os de outros pesquisadores [13,
15]. Na Fig. 2 é mostrado o diagrama de dosagem para a produção dos 50 traços de concreto determinados pelo projeto experimental. O diagrama foi produzido utilizando-se de um traço médio 1:5 (cimento:agregados, em massa), com o intuito de se determinar o teor ideal de argamassa, que foi de $51 \%$, para uma relação água/cimento de 0,54 , obtendo-se um abatimento pelo método do tronco de cone (slump test) de $12 \pm 2 \mathrm{~cm}$. Em seguida, fez-se mais 3 traços auxiliares, um mais rico (teor de agregados igual a 3,5) e dois mais pobres (teor de agregados iguais a 6,5 e 7,5), variando-se o teor de água da mistura até se alcançar o abatimento desejado. De cada traço confeccionado moldaram-se 6 corpos-de-prova, os quais foram rompidos 2 aos 7 dias, 2 aos 14 dias e 2 aos 28 dias de idade, produzindo-se então as curvas resistência à compressão versus relação água/cimento, para as respectivas idades. A Tabela VI traz a composição do traço 1 da Tabela I, de relação a/c igual a 0,46 , feito com agregados naturais.

\section{Considerações iniciais sobre os modelos produzidos}

O projeto experimental utilizado envolve 7 variáveis independentes. $\mathrm{O}$ experimento foi fracionado de forma a reduzir o número total de corpos-de-prova a serem ensaiados. Os tratamentos foram definidos de acordo com um projeto composto de segunda ordem, o qual permite testar termos lineares e quadráticos. Os dados coletados permitiram gerar modelos relacionando as variáveis de resposta (resistência à compressão, módulo de deformação, retração por secagem e volume de poros permeáveis) com as variáveis independentes, podendo-se determinar modelos simples, como a regressão linear múltipla, ou modelos complexos, como a regressão não linear. Entretanto, este trabalho se restringirá a discutir a influência dos agregados graúdos e miúdos reciclados de cerâmica vermelha sobre o comportamento dos concretos. Para um melhor entendimento dos modelos fez-se abreviações dos nomes das variáveis independentes e das variáveis de resposta utilizadas, que são mostrados na Tabela VII.

Juntamente com a construção dos modelos foi feita uma análise dos resíduos padronizados. Os dados coletados que geraram resíduos padronizados com módulo maior que 3 foram eliminados da análise, sendo que estes foram somente os valores da resistência à compressão e do módulo de deformação para o traço 3 . Todos os modelos propostos apresentaram coeficiente de determinação $\left(\mathrm{R}^{2}\right)$ superiores a $95 \%$. Para os resultados apresentados pela resistência à compressão e pelo módulo de deformação, as análises apresentadas a seguir foram desenvolvidas apoiadas em uma rotina de regressão linear, que mesmo sendo relativamente simples, apresentaram bons resultados. Como este tipo de regressão não apresentou bons resultados para o volume de poros permeáveis, utilizou-se uma regressão não-linear para modelar os resultados dessas variáveis. Foram tentados alguns modelos mais complexos, mas o ganho estatístico foi pequeno. Sendo assim, optou-se pelos modelos mais simples. Os modelos propostos a seguir são válidos apenas para concretos produzidos com o cimento do tipo $\mathrm{CP} \mathrm{V}$, o 
Tabela VII - Simbologia das variáveis independentes e das variáveis de resposta utilizadas nos modelos. [Table VI - Independent and dependent variables symbol used in the models.]

\begin{tabular}{ccc}
\hline Símbolo & Nome & Variável \\
& Tipo \\
\hline rvg & $\begin{array}{c}\text { percentual do agregado graúdo natural } \\
\text { substituído pelo agregado reciclado } \\
\text { graúdo de cerâmica vermelha }\end{array}$ & independente \\
& percentual do agregado miúdo natural \\
rvm & $\begin{array}{c}\text { substituído pelo agregado miúdo } \\
\text { reciclado de cerâmica vermelha }\end{array}$ & \\
& relação água/cimento & independente \\
$\mathrm{f}_{\mathrm{c}}$ & resistência à compressão aos 28 dias & independente \\
$\mathrm{E}_{\mathrm{c}}$ & módulo de deformação aos 28 dias & de resposta \\
$\mathrm{VPP}$ & volume de poros permeáveis aos 224 & de resposta \\
& & de resposta
\end{tabular}

qual foi utilizado nos experimentos laboratoriais, e para os agregados reciclados de cerâmica vermelha produzidos com britadores do tipo mandíbula. Para utilizarem-se tais modelos para inferir a resistência à compressão, o módulo de deformação e o volume de poros permeáveis de concretos produzidos com outros tipos de cimentos ou com agregados reciclados de cerâmica vermelha produzidos com outros tipos de britadores é necessário determinar experimentalmente coeficientes que venham a corrigir os resultados propostos pelos modelos, majorando ou minorando tais valores.

\section{Resistência à compressão}

O modelo determinado para representar a resistência à compressão é representado pela equação B.

$$
f_{c}=\left(\frac{102,43}{5,38^{a / c}}\right) \cdot[1-(\% \text { substituído })]
$$

O primeiro termo entre parênteses refere-se à resistência dos corpos-de-prova sem a substituição do agregado natural pelo reciclado, seguindo a Lei de Abrams, que é função da relação água/cimento. Este termo foi definido previamente, a partir de uma análise dos valores obtidos quando a relação água/cimento era igual a $0,46,0,60$ e 0,74 , sendo estabelecido de forma a gerar o melhor ajuste possível, ou seja, minimizar os erros de previsão.

O segundo termo, entre colchetes, define um percentual a ser aplicado sobre a resistência original, modificando-a em função da substituição do agregado natural pelo reciclado de cerâmica vermelha. Então essa modificação da resistência é função do percentual de agregado natural substituído pelo agregado reciclado, conforme a equação C. Se a modificação da resistência for positiva, haverá uma perda de resistência, e caso seja negativa, haverá um acréscimo.

Modificação da resistência=f $(\%$ substituído $)$
Fez-se então uma regressão múltipla utilizando a modificação da resistência como variável de resposta e os percentuais dos agregados naturais substituídos pelos agregados reciclados de cerâmica vermelha como variáveis dependentes. O resultado aponta que as variáveis dependentes utilizadas exercem efeito significativo sobre a modificação da resistência dos concretos com agregado reciclado. O modelo da modificação da resistência encontrado possui um excelente coeficiente de determinação $\left(\mathrm{R}^{2}=98 \%\right)$, estando descrito na equação D.

Modificação da resistência=0,371.rvg - 0,138.rvm

A tentativa de inserir termos quadrados (como rvg.rvg, por exemplo) ou interações (como rvg.rvm, por exemplo) não melhorou o ajuste, sendo portanto, estes termos mais complexos, desprezados. Na Fig. 3 tem-se o resultado da análise não linear realizada para a resistência à compressão com todos os tipos de agregados reciclados utilizados no projeto experimental, entretanto, como já mencionado, neste artigo se considerará somente a influência dos agregados reciclados de cerâmica vermelha ( $r v g$ e $r v m)$. Por fim, o modelo que estima a resistência em função do percentual de substituição dos agregados naturais pelos reciclados de cerâmica vermelha e da relação água/cimento encontra-se na equação $\mathrm{E}$.

$$
f_{c}=\left(\frac{102,43}{5,38^{a / c}}\right) \cdot[1-(0,371 \cdot r v g-0,138 \cdot r v m)]
$$

Nesse modelo os percentuais de substituição dos agregados miúdo ou graúdo pelos reciclados devem ser informados na escala de $0(0 \%)$ a $1(100 \%)$, enquanto que a relação água/cimento está expressa na escala usual, variando de 0,4 a 0,8 . Convém salientar que o somatório dos percentuais de substituição dos agregados naturais pelo reciclados devem ser no máximo igual a $1(100 \%)$, para cada 


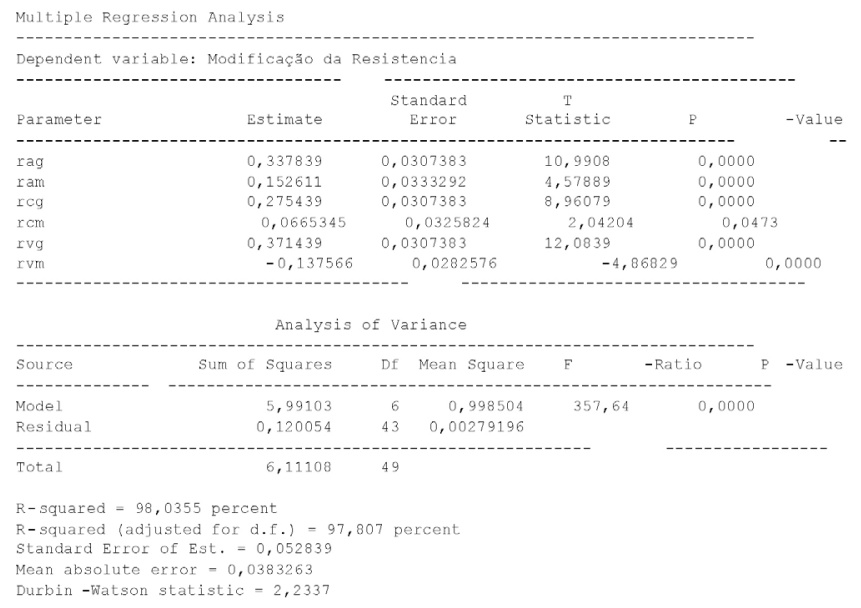

Figura 3: Análise de regressão múltipla para a resistência à compressão.

[Figure 3: Multiple regression analysis for axial strength.]

tipo de agregado (graúdo e miúdo). Conforme a equação E, a substituição do agregado graúdo natural pelo graúdo reciclado de cerâmica vermelha resulta em uma redução da resistência e a substituição do agregado miúdo natural pelo miúdo reciclado de cerâmica vermelha resulta em um acréscimo da resistência. De posse do modelo descrito na equação E, geraram-se curvas que ilustram a influência de cada tipo de agregado reciclado, para os teores de substituição de $0 \%$, $50 \%$ e $100 \%$, para as relações água/cimento intermediárias, ou seja, 0,46, 0,6 e 0,74. Em função dos valores obtidos para se gerar as curvas, montou-se uma tabela com as perdas e ganhos de resistência para cada caso. As curvas e a tabela encontram-se dispostos na Fig. 4 e na Tabela VIII.

Na Fig. 4 pode-se observar a influência da relação água/ cimento sobre o desempenho da resistência à compressão dos concretos, uma vez que para teores de substituição idênticos, as resistências dos concretos de baixa relação água/cimento são superiores às resistências dos concretos de alta relação água/cimento. Conforme os dados da Tabela VIII, ao se passar a relação água/cimento de 0,46 para 0,60 , a resistência à compressão é reduzida em $21 \%$, enquanto que ao passála de 0,46 para 0,74 , esta é diminuída em 38\%. Quanto maior a relação água/cimento, maior será a probabilidade da formação de um filme de água sobre a superfície dos agregados e, com a formação desse filme, mais fraca será a zona de transição entre a pasta de cimento e o agregado. Além disso, quanto maior a relação água/cimento, maior será a porosidade total do concreto e, consequentemente, menos resistente o concreto será [30]. Pode-se observar também que a substituição do agregado graúdo natural pelo graúdo reciclado de cerâmica vermelha produz um efeito negativo sobre a resistência à compressão, provocando uma redução desta propriedade. Entretanto, observou-se que a substituição do agregado miúdo natural pelo miúdo reciclado de cerâmica vermelha produz um efeito positivo, aumentando a resistência dos concretos produzidos com este tipo de agregado reciclado. A substituição do agregado graúdo produz um efeito maior do que a substituição

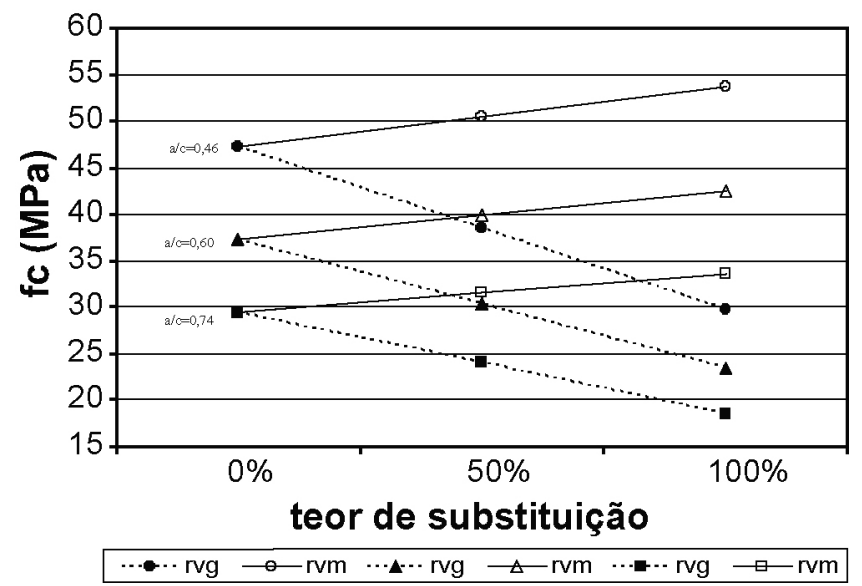

Figura 4: Comportamento da resistência à compressão em função dos teores de substituição do agregado natural pelo reciclado de cerâmica vermelha, para relações água/ cimento iguais a $0,46,0,60$ e 0,74 .

[Figure 4: Axial strength behavior when natural aggregate was replaced by red ceramic recycled aggregate for water/cement ratio equal to 0.46, 0.60 and 0.74.]

Tabela VIII - Desempenho da resistência à compressão dos concretos quando feita a substituição do agregado natural pelo agregado reciclado de cerâmica vermelha.

[Table VIII - Concrete's axial strength behavior when natural aggregate was replaced by red ceramic recycled aggregate.]

\begin{tabular}{ccc}
\hline $\begin{array}{c}\text { Teor de } \\
\text { substituição }\end{array}$ & $\begin{array}{c}\text { Agregado } \\
\text { graúdo reciclado } \\
\text { de cerâmica } \\
\text { vermelha (rvg) }\end{array}$ & $\begin{array}{c}\text { Agregado miúdo } \\
\text { reciclado de } \\
\text { cerâmica vermelha } \\
\text { (rvm) }\end{array}$ \\
\hline $0 \%$ & 1,00 & 1,00 \\
$50 \%$ & 0,81 & 1,07 \\
$100 \%$ & 0,63 & 1,14 \\
0,46 & Relação água/cimento & 0,74 \\
1,00 & 0,60 & 0,62 \\
\hline
\end{tabular}

do agregado miúdo, em função da magnitude dos seus coeficientes, conforme pode ser observado na Equação E. Para o agregado graúdo, o concreto tem uma redução de $19 \%$ e $37 \%$ na sua resistência à compressão, ao se substituir $50 \%$ e $100 \%$, respectivamente, dos agregados naturais pelos reciclados de cerâmica vermelha, enquanto que o concreto tem um aumento de $7 \%$ e $14 \%$ na sua resistência à compressão, ao se substituir $50 \%$ e $100 \%$, respectivamente, dos agregados miúdos naturais pelos agregados miúdos reciclados de cerâmica vermelha. Embora não se tenha realizado ensaios de pozolanicidade no agregado miúdo reciclado de cerâmica vermelha utilizado, há pesquisas que comprovam o efeito pozolânico deste tipo de agregado $[18,31]$. Portanto, o acréscimo na resistência dos concretos quando se usa o agregado miúdo reciclado de cerâmica 
vermelha pode ter ocorrido devido a reações pozolânicas, uma vez que tais estas melhoram a matriz e a zona de transição entre a pasta e o agregado e, consequentemente, melhoram as propriedades mecânicas de concretos e argamassas produzidas com este tipo de agregado miúdo reciclado. Tais incrementos também foram observados por outros pesquisadores [18, 31-33]. Outra justificativa para o melhor desempenho dos concretos com agregados miúdos reciclados é devido à aspereza da superfície destes agregados, a qual propicia uma melhor ligação entre a matriz de cimento e os agregados reciclados [13]. Por sua vez, uma possível causa para a redução da resistência à compressão dos concretos com agregados graúdos reciclados de cerâmica vermelha é a forma do agregado graúdo reciclado. Embora não se tenha realizado ensaios de índice de forma nos agregados utilizados, pesquisas relatam que o agregado graúdo reciclado de cerâmica vermelha geralmente é mais angular que o agregado graúdo natural, não propiciando uma eficiente mistura, produzindo assim concretos com uma maior quantidade de vazios, mesmo tendo a mesma distribuição granulométrica dos demais [34]. Além disso, este tipo de agregado normalmente tem uma resistência mecânica inferior à do agregado natural, o que contribui para que a resistência dos concretos produzidos com estes agregados reciclados seja menor que a resistência dos concretos convencionais, quando se produz concretos em que a resistência da matriz é superior à resistência dos agregados [32, 35].

\section{Módulo de deformação}

O mesmo procedimento utilizado para a construção do modelo da resistência à compressão foi adotado na construção do modelo do módulo de deformação. Pode-se observar na Fig. 5 o resultado da análise linear para o módulo de deformação com todos os tipos de agregados reciclados utilizados no projeto experimental, entretanto, como já

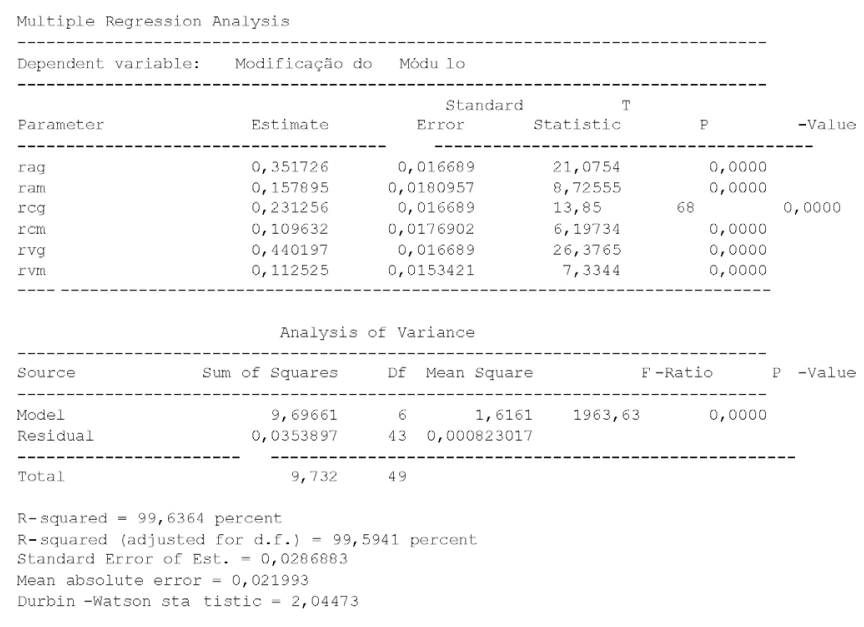

Figura 5: Análise de regressão múltipla para o módulo de deformação.

[Figure 5: Multiple regression analysis for module of deformation.] mencionado, neste artigo se considerará somente a influência dos agregados reciclados de cerâmica vermelha ( $r v g$ e $r v m$ ). $\mathrm{O}$ modelo determinado para representar a propriedade do concreto em estudo está descrito na Equação F.

$$
\mathrm{E}_{\mathrm{c}}=\left(\frac{21,69}{\mathrm{a} / \mathrm{c}^{0,5}}\right) \cdot[1 \text { - (substituído) }]
$$

O primeiro termo entre parênteses refere-se ao módulo de deformação do concreto com agregados naturais e é função somente da relação água/cimento. Este termo foi definido a partir de uma análise dos valores obtidos para o módulo quando a relação água/cimento dos concretos era igual a $0,46,0,60$ e 0,74 , sendo estabelecido de maneira a gerar o melhor ajuste possível entre os dados coletados, reduzindose assim os erros de previsão.

O segundo termo, [1- (\% substituido)], define um percentual a ser aplicado sobre o módulo original, podendo aumentá-lo ou reduzi-lo em função da substituição do agregado natural pelo reciclado. Essa modificação do módulo é, então, função do percentual de agregado natural substituído pelo agregado reciclado e está representado na equação $\mathrm{G}$.

Modificação do módulo=f (\%substituído)

Similarmente ao que foi feito para a modificação da resistência, fez-se para a modificação do módulo uma regressão múltipla, utilizando-a como variável de resposta, e os percentuais dos agregados naturais substituídos pelos agregados reciclados de cerâmica vermelha como variáveis dependentes. O modelo encontrado expressa a modificação do módulo em função da substituição do agregado natural pelo reciclado. Este possui um excelente coeficiente de determinação $\left(\mathrm{R}^{2}=99 \%\right)$, estando expresso na equação $\mathrm{H}$.

$$
\text { Modificação do módulo=0,440.rvg + 0,113.rvm }
$$

Este modelo, por ter um excelente coeficiente de determinação, desprezou-se os termos quadrados (como rvg.rvg, por exemplo) ou as interações (como rvg.rvm, por exemplo). Então, o modelo final de regressão linear que estima o módulo de deformação em função do percentual de substituição dos agregados naturais pelos reciclados e da relação água/cimento é o expresso na equação I.

$$
\mathrm{E}_{\mathrm{c}}=\left(\frac{21,69}{\mathrm{a} / \mathrm{c}^{0,5}}\right) \cdot[1-(0,440 \cdot \mathrm{rvg}-0,113 \cdot \mathrm{rvm})]
$$

Como condições de contorno, os percentuais de substituição dos agregados miúdo ou graúdo pelos reciclados devem ser informados na escala de $0(0 \%)$ a $1(100 \%)$ e a relação água/cimento de 0,4 a 0,8 . É necessário também que o somatório dos percentuais de substituição dos agregados naturais pelo reciclados devem ser no máximo igual a 1 (100\%), para cada tipo de agregado (graúdo e miúdo). De acordo com o modelo apresentado, a substituição do agregado natural pelo reciclado de cerâmica vermelha resulta em uma redução do módulo de deformação, tanto 


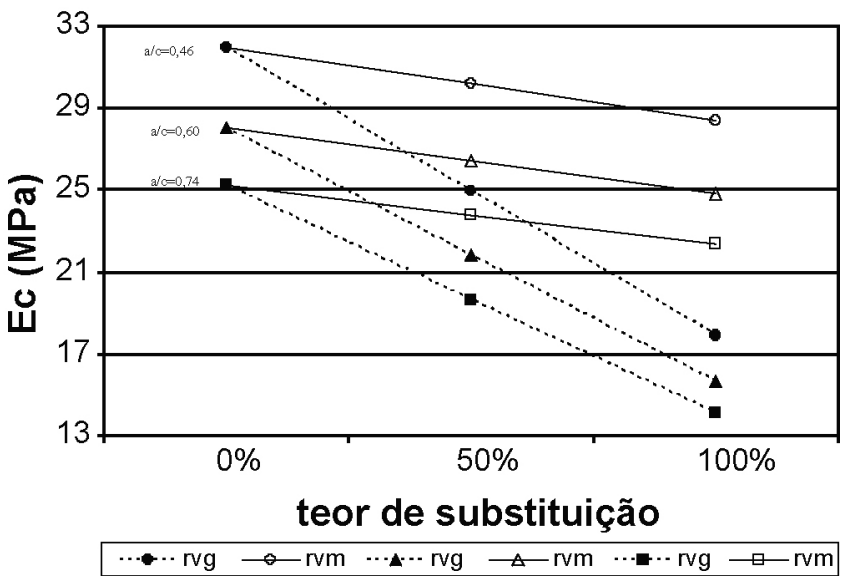

Figura 6: Comportamento do módulo de deformação em função dos teores de substituição do agregado natural pelo reciclado de cerâmica vermelha, para relações água/cimento iguais a 0,46, 0,60 e 0,74 .

[Figure 6: Module of deformation behavior when natural aggregate was replaced by red ceramic recycled aggregate for water/cement ratio equal to $0.46,0.60$ and 0.74 .]

Tabela IX - Desempenho do módulo de deformação dos concretos quando feita a substituição do agregado natural pelo agregado reciclado de cerâmica vermelha.

[Table IX - Concrete's modulus of deformation behavior when natural aggregate was replaced by red ceramic recycled aggregate.]

\begin{tabular}{ccc}
\hline $\begin{array}{c}\text { Teor de } \\
\text { substituição }\end{array}$ & $\begin{array}{c}\text { Agregado graúdo } \\
\text { reciclado de cerâmica } \\
\text { vermelha (rvg) }\end{array}$ & $\begin{array}{c}\text { Agregado } \\
\text { miúdo reciclado } \\
\text { de cerâmica } \\
\text { vermelha (rvm) }\end{array}$ \\
\hline $0 \%$ & 1,00 & 1,00 \\
$50 \%$ & 0,78 & 0,94 \\
$100 \%$ & 0,56 & 0,89 \\
& Relação água/cimento \\
0,46 & 0,60 & 0,74 \\
1,00 & 0,88 & 0,79 \\
\hline
\end{tabular}

para a substituição do graúdo quanto para a do agregado miúdo. De maneira semelhante ao modelo para a resistência à compressão anteriormente apresentado, observa-se também que a substituição do agregado graúdo produz um efeito maior sobre o módulo de deformação do que a substituição do agregado miúdo, como se pode observar em função da magnitude dos seus coeficientes. De posse do modelo expresso na equação I, curvas que ilustra a influência dos agregados graúdos e miúdos reciclados de cerâmica vermelha foram geradas, para teores de substituição de $0 \%$, $50 \%$ e $100 \%$ e para as relações água/cimento $0,46,0,6$ e 0,74 . Gerou-se também uma tabela com as perdas do módulo para cada tipo de substituição. As curvas e a tabela encontram-se dispostas na Fig. 6 e na Tabela IX.

Na Fig. 6 pode-se observar que quanto maior a relação água/cimento, mais deformável é o concreto produzido, ou seja, este possui um menor módulo de deformação. De maneira coerente, conforme os dados da Tabela IX, os concretos de relação água/cimento 0,60 e 0,74 possuem módulos $12 \%$ e $21 \%$ menores, respectivamente, que o módulo do concreto de relação água/cimento 0,46. A substituição de tanto do agregado graúdo natural, quanto do miúdo natural, pelos seus respectivos agregados reciclados de cerâmica vermelha, diminuem o módulo de deformação dos concretos. Entretanto, o agregado graúdo de cerâmica vermelha exerce a maior influência sobre o módulo de deformação, alcançando uma perda de $22 \%$ no valor do módulo, para o teor de substituição de $50 \%$, e de $44 \%$, para $100 \%$ de substituição. Esta maior influência do agregado graúdo reciclado de cerâmica vermelha sobre o módulo também foi encontrada em outros trabalhos [6, $31,36]$. Tais trabalhos apontam perdas de $44 \%$ a $50 \%$ no módulo de deformação, para $100 \%$ de substituição, sendo tais valores próximos ao sugerido pelo modelo proposto. Ao se analisar o resultado para a substituição do agregado miúdo natural pelo miúdo reciclado de cerâmica vermelha, observa-se que para $50 \%$ de substituição, o concreto apresenta uma perda de $6 \%$ no módulo de deformação dos concretos, e para $100 \%$ de substituição, a perda é de $11 \%$, resultados estes próximos aos encontrados na literatura [31]. Segundo o modelo encontrado, quando substituídos conjuntamente, os agregados miúdos e graúdos reciclados potencializam o efeito redutor no módulo de deformação dos concretos, atingindo $55 \%$ de redução, resultado este coerente com os encontrados na bibliografia [32]. O módulo de deformação do concreto depende da fração volumétrica, da massa específica e do módulo de deformação dos seus principais constituintes (matriz de cimento e agregados) e das características da zona de transição entre a matriz e o agregado. Como a massa específica é inversamente proporcional à porosidade, fatores que afetam a porosidade do agregado, da matriz de cimento e da zona de transição, afetam também o módulo de deformação do concreto [37]. Por sua vez, o módulo de deformação do agregado graúdo também está ligado à sua própria porosidade e, em um menor grau de valor, ao diâmetro máximo, à forma, à textura, à granulometria e à composição mineralógica do próprio agregado. Portanto, a rigidez do agregado graúdo controla a capacidade de restrição da deformação da matriz e esta rigidez é determinada pela porosidade do agregado [37]. Como os agregados reciclados de cerâmica vermelha possuem as características anteriormente citadas diferentes das dos agregados naturais, ao se substituir o agregado natural pelo agregado reciclado, modificações são introduzidas nos concretos produzidos. Por meio dos dados da Tabela IV e V, observa-se que os agregados graúdos e miúdos reciclados de cerâmica vermelha são mais porosos que os agregados naturais, uma vez que apresentam maiores absorções e menores massas específicas que os agregados naturais.

Analisando os resultados compilados na Tabela IX, também se ratifica a menor influência dos agregados miúdos reciclados sobre o módulo de deformação dos concretos. Tal 
comportamento foi semelhantemente encontrado em outras pesquisas em concretos com agregados reciclados de cerâmica vermelha [18]. Então, ao se substituir os agregados miúdos naturais pelos miúdos reciclados, alterações são introduzidas nas propriedades da matriz de cimento do concreto, e ao se substituir os graúdos naturais pelos graúdos reciclados, as características de deformabilidade do concreto como um todo são modificadas, uma vez que o agregado graúdo reciclado de cerâmica vermelha é mais deformável que o agregado graúdo natural, tornando, assim, o concreto mais deformável.

\section{Volume de poros permeáveis}

De posse dos resultados coletados no ensaio de determinação do volume de poros permeáveis (VPP), utilizando-se uma regressão múltipla não linear, foi realizada uma análise estatística dos dados propondo-se um modelo matemático que relacionasse a variável de resposta (VPP) com as variáveis independentes. Tem-se na Fig. 7 o resultado da análise não linear realizada para o VPP com todos os agregados reciclados utilizados nos experimentos, contudo, para este artigo, serão contemplados no modelo apenas os agregados reciclados de cerâmica vermelha ( $r v g$ e $r v m$ ). O modelo obtido está descrito na Equação $\mathrm{K}$, o qual possui um coeficiente de determinação $\left(\mathrm{R}^{2}\right)$ bastante satisfatório, de valor igual a $97 \%$.

$\operatorname{VPP}(\%)=15,1 .\left(\mathrm{a} / \mathrm{c}^{0,23}\right) \cdot(1+0,64 \cdot \mathrm{rvg}) \cdot(1+0,29 \cdot \mathrm{rvm})$

De maneira semelhante aos outros modelos previamente apresentados, nesse modelo os percentuais de substituição dos agregados miúdo ou graúdo pelos reciclados devem ser informados na escala de $0(0 \%)$ a $1(100 \%)$ e a relação

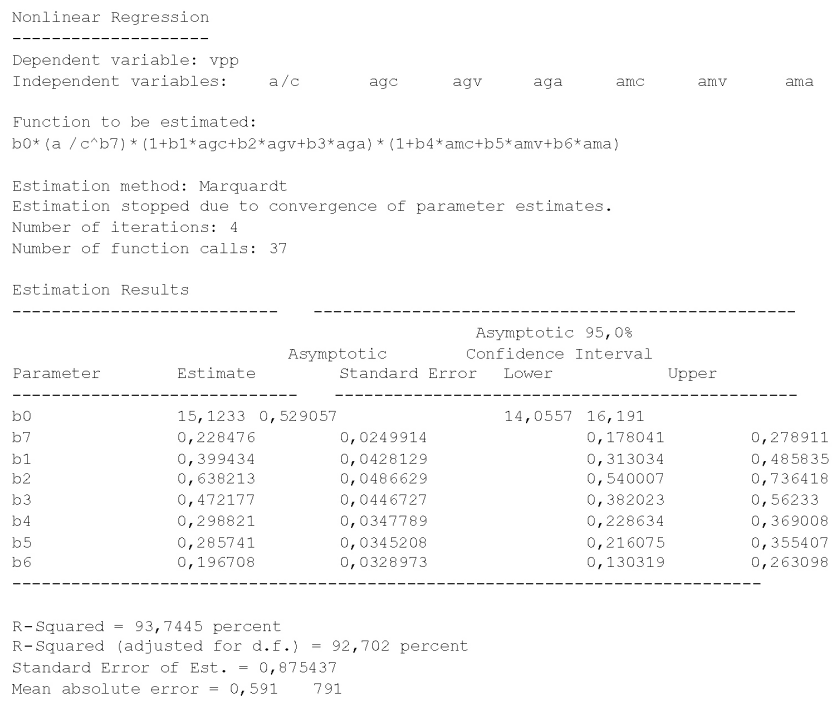

Figura 7: Análise de regressão múltipla para o módulo de deformação.

[Figure 7: Multiple regression analysis for module of deformation.]

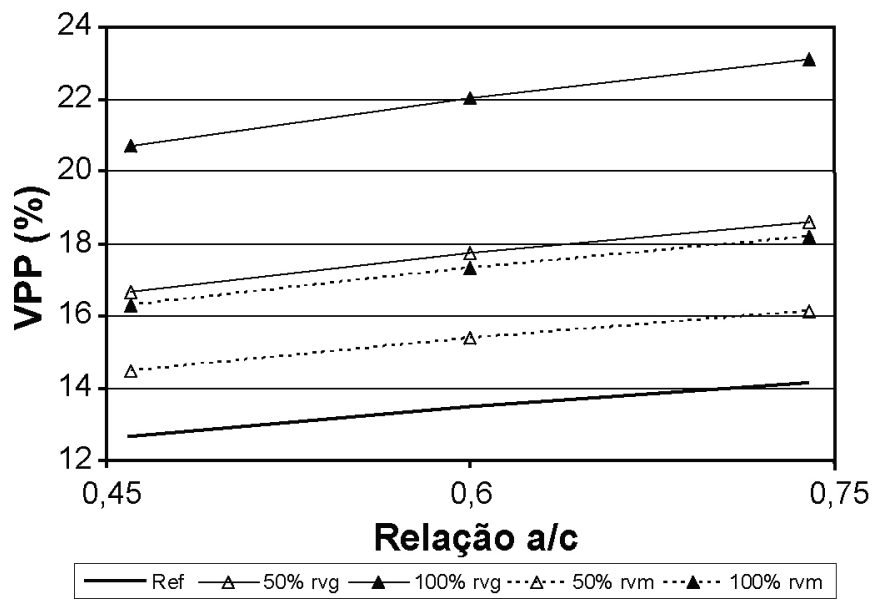

Figura 8: Comportamento do VPP, aos 224 dias, em função dos teores de substituição do agregado natural pelo reciclado e da relação água/cimento.

[Figure 8: VPP behavior, at 224 age day, function of tenor of natural aggregate replacement by red ceramic recycled aggregate and of a water/cement ratio.]

Tabela XI - Desempenho da retração por secagem dos concretos quando feito a substituição do agregado natural pelo agregado reciclado para a idade de 224 dias.

[Table XI - Concrete's shrinkage behavior, at 224 age day, when natural aggregate was replaced by red ceramic recycled aggregate.]

\begin{tabular}{ccc}
\hline $\begin{array}{c}\text { Teor de } \\
\text { substituição }\end{array}$ & $\begin{array}{c}\text { Agregado graúdo } \\
\text { reciclado de } \\
\text { cerâmica vermelha } \\
\text { (rvg) }\end{array}$ & $\begin{array}{c}\text { Agregado miúdo } \\
\text { reciclado de } \\
\text { cerâmica vermelha } \\
\text { (rvm) }\end{array}$ \\
\hline $0 \%$ & 1,00 & 1,00 \\
$50 \%$ & 1,32 & 1,15 \\
$100 \%$ & 1,64 & 1,29 \\
& Relação água/cimento \\
0,46 & 0,60 & 0,74 \\
1,00 & 1,06 & 1,12 \\
\hline
\end{tabular}

água/cimento de 0,4 a 0,8 . O somatório dos percentuais de substituição dos agregados naturais pelo reciclados devem ser no máximo igual a $1(100 \%)$, para cada tipo de agregado (graúdo e miúdo). Utilizando-se o modelo apresentado na equação K, geraram-se curvas, as quais se encontram na Fig. 8 , que ilustram a influência da substituição de $0 \%, 50 \%$ e $100 \%$ do agregado graúdo e do miúdo natural pelos seus respectivos reciclados de cerâmica vermelha e da variação da relação água/cimento de 0,46 para 0,60 e para 0,74 . Na Tabela XI podem-se observar os aumentos e as diminuições do VPP para estes casos. Conforme a Fig. 8 e os dados da Tabela XI, quandoé feita a substituição dos agregados naturais pelos reciclados, há um acréscimo do VPP do concreto obtido, independentemente do tipo (graúdo ou miúdo) de agregado reciclado utilizado. Entretanto, a substituição do 
agregado graúdo natural pelos reciclados produz um efeito superior ao da substituição do agregado miúdo natural pelos reciclados. Tais resultados são coerentes com os previamente apresentados para a resistência à compressão e para o módulo de deformação, em que a substituição do agregado graúdo natural pelo graúdo reciclado produziu um efeito maior do que a substituição do agregado miúdo natural pelo miúdo reciclado, uma vez que quanto maior o VPP do concreto espera-se que esse apresente mais vazios e, consequentemente, uma menor resistência e um menor módulo.

Por meio da Fig. 8 e da Tabela XI pode-se também observar uma variação no VPP quando se modifica a relação água/cimento, independentemente do tipo de agregado, sendo que quanto maior a relação água/cimento, maior o VPP. Este resultado é coerente com o esperado, uma vez que quanto maior é a quantidade de água na mistura, mais poroso é o concreto produzido. A substituição do agregado graúdo natural pelo graúdo reciclado de cerâmica vermelha propicia os maiores valores para o VPP, com acréscimo de $32 \%$ e $64 \%$ para $50 \%$ e $100 \%$ de substituição, respectivamente, quando comparado com o concreto de referência. Para o concreto com o agregado miúdo reciclado de cerâmica vermelha, os acréscimos nos valores do VPP foram basicamente metade dos apresentados para os concretos com o agregado graúdo reciclado, uma vez que os primeiros obtiveram acréscimos de $15 \%$ e $29 \%$ nos valores do VPP, para $50 \%$ e $100 \%$ de substituição, respectivamente, quando comparados ao concreto de referência.

\section{CONCLUSÕES}

Foi possível modelar o comportamento da resistência à compressão, do módulo de deformação e do volume de poros permeáveis (VPP) dos concretos produzidos com a substituição dos agregados graúdos e miúdos naturais pelos seus respectivos agregados reciclados de cerâmica vermelha. $\mathrm{O}$ modelo da retração por secagem dos agregados apresentou um coeficiente de determinação insatisfatório, tendo sido portanto descartado. Entretanto, todos os demais modelos propostos para as outras propriedades (resistência à compressão, módulo de deformação e volume de poros permeáveis) obtiveram excelentes coeficientes de determinação. Simulações realizadas utilizando-se os modelos propostos apontam que a substituição do agregado miúdo natural pelo miúdo reciclado resulta em um acréscimo da resistência à compressão dos concretos produzidos e para a substituição do agregado graúdo natural pelo graúdo reciclado, um decréscimo. Para as demais propriedades do concreto estudadas, observou-se que a utilização dos agregados reciclados, tanto graúdo quanto miúdo, influi negativamente no comportamento do concreto, sendo que o agregado do tipo graúdo reciclado exerceu em todas as propriedades, uma maior influência.

\section{AGRADECIMENTOS}

Ao NORIE (Núcleo Orientado à Inovação da Edificação) da UFRGS, pelo apoio na realização dos experimentos, à Faculty of Engeneering da University of Technology, Sydney (UTS), pela ajuda no desenvolvimento dos modelos e à Coordenação de Aperfeiçoamento de Pessoal de Nível Superior (CAPES) pelo financiamento deste trabalho por meio do PQI 106/03-8 (CEFET/CE-EESC/USP).

\section{REFERÊNCIAS}

[1] J. C. Marques Neto, Gestão dos resíduos de construção e demolição no Brasil, $1^{\text {a }}$ Ed., Ed. Rima, S. Carlos, SP (2005) 16.

[2] V. M. John. Reciclagem de entulho para a produção de materiais de construção, A. P. Carneiro, I. A. S. de Brum, J. C. S. Cassa. Ed. Edufba, Salvador, BA (2001) 27.

[3] S. E. Zordan, Utilização do entulho como agregado, na confecção do concreto, Fac Eng. Civil, UNICAMP, Diss. Mestrado, Campinas, SP (1997)

[4] G. Bianchini, E. Marrocchino, R. Tassinari, C. Vaccaro, Waste Management 25 (2005) 149.

[5] T. Tu, Y. Chen, C. Hwang, Cem. Concr. Res. 36 (2006) 943.

[6] T. C. Hansen, Recycling of Demolished Concrete and Masonry, Ed. T. C. Hansen, E \& FN Spon, Londres, UK (1992) 1.

[7] B. E. C. Quadros, A. M. V. Oliveira. Reciclagem de entulho para a produção de materiais de construção, A. P. Carneiro, I. A. S. de Brum, J. C. S. Cassa. Ed. Edufba, Salvador, BA (2001) 116.

[8] C. S. Poon, T. W. Ann, N. G L. H. Yu, Resources, Conservation Recycling 32 (2001) 157.

[9] T. Esin, N. Cosgun, Building Environment 42 (2007) 1667.

[10] U. Leal, Techne: revista de tecnologia da construção 10 (2001) 58.

[11] A. E. B. Cabral, Modelagem de propriedades mecânicas e de durabilidade de concretos produzidos com agregados reciclados, considerando-se a variabilidade da composição do RCD, Esc. Eng. S. Carlos, USP, Tese Dr., S. Carlos, SP (2007).

[12] A. Henrichsen, Int. Workshop Recycled Aggregate, Niigata, Japão (2000) 1.

[13] A. R. Kahloo, ACI Materials J. 91 (1994) 401.

[14] R. M. Senthamarai, P. D. Manoharan, Cem. Concr. Composites 27 (2005) 910.

[15] C. M. F. Vieira, E. T. A. de Souza, S. N. Monteiro, Cerâmica 49, 312 (2003) 245-250

[16] J. L. D. Ribeiro, C. S. T. Caten, Projeto de experimentos, Ed. FEEng, UFRGS, Porto Alegre, RS (2001).

[17] M. C. C. Werkema, S. Aguiar, Planejamento e análise de experimentos: como identificar e avaliar as principais variáveis influentes em um processo, Ed. Fundação Christiano Ottoni, Belo Horizonte, MG (1996).

[18] M. A. Leite, Avaliação de propriedades mecânicas de concretos produzidos com agregados reciclados de resíduos de construção e demolição, Eng. Civil, UFRGS, Tese Dr., Porto Alegre, RS (2001). 
[19] G. L. Vieira, Estudo do processo de corrosão sob a ação de íons cloreto em concretos obtidos a partir de agregados reciclados de resíduos de construção e demolição, Eng. Civil, UFRGS, Diss. Mestrado, Porto Alegre, RS (2003).

[20] Y. Liu, Y. Tyan, T. Chang, C. Chang, Cem. Concr. Res. 34 (2004) 1373.

[21] ABNT - Associação Brasileira de Normas Técnicas, Concreto - Ensaio de compressão de corpos-de-prova cilíndricos, NM 101, Rio de Janeiro, RJ (1996).

[22] ABNT - Associação Brasileira de Normas Técnicas, Concreto - Determinação do módulo estático de elasticidade à compressão, NBR 8522, Rio de Janeiro, RJ (2008).

[23] ASTM - American Society for Testing and Materials, Standard test method for density, absorption, and voids in hardened concrete, ASTM C 642, Pennsylvania, EUA (2006).

[24] A. E. B. Cabral, D. C. C. Dal Molin, J. L. D. Ribeiro, Compressive strength and deformation modelling of recycled aggregate concrete, $7^{\text {th }}$ Int. Cong. Concrete Construction's Sustenaible Option, Dundee (2008).

[25] A. E. B. Cabral, V. Schalch, D. C. C. Dal Molin, J. L. D. Ribeiro, R. S. Ravindrarajah, Ultimate shrinkage modeling of recycled aggregate concrete, PSU-UNS Int. Conf. Eng. Environment - ICEE-2007, Phuket (2007).

[26] P. R. L. Helene, P. Terzian, Manual de dosagem e controle do concreto, Ed. PINI, S. Paulo, SP (1992).

[27] ABNT - Associação Brasileira de Normas Técnicas, Agregados reciclados de resíduos sólidos da construção civil
- Utilização em pavimentação e preparo de concreto sem função estrutural - Requisitos, NBR 15116, Rio de Janeiro, RJ (2004).

[28] ABNT - Associação Brasileira de Normas Técnicas, Concreto - Procedimento para moldagem e cura de corposde-prova, NBR 5738, Rio de Janeiro, RJ (2008).

[29] ASTM - American Society for Testing and Materials, Standard test method for length change of hardened hydraulic-cement mortar and concrete, ASTM C 157, Pennsylvania, EUA (2008).

[30] N. Otsuki, S. Miyazato, Int. Workshop Recycled Aggregate, Niigata, Japão (2000) 77.

[31] S. M. Levy, Contribuição ao estudo da durabilidade de concretos produzidos com resíduos de concreto e alvenaria, EPUSP, Tese Dr., S. Paulo, SP (2001).

[32] R. R. Schulz, Ch. F. Hendricks, Recycling of demolished concrete and masonry, Ed. T. C. Hansen, E \& FN Spon, Londres, UK (1992) 164.

[33] J. M. Khatib, Cem. Concr. Res. 35 (2005) 763.

[34] F. M. Khalaf, J. Mater. Civil Eng. 18 (2006) 518.

[35] J. de Brito, A. S. Pereira, J. R. Correia, Cem. Concr. Composites 27 (2005) 429.

[36] Rilem Recommendation, Mater. Structures 27 (1994) 557.

[37] P. K. Mehta, P. J. M. Monteiro, Concreto: estruturas, propriedades e materiais, Ed. Pini, S. Paulo, SP (1994).

[38] M. Tavakoli, P. Soroushian, Concr. Int.18 (1996) 58.

(Rec. 28;04;2008, Rev. 26;12;2008, Ac. 19;02;2009) 